\title{
Association between a body shape index and abdominal aortic calcification in the general population: National Health and Nutrition Examination Survey 2013-2014
}

\section{Zhenwei Wang (D 1229445463@qq.com )}

Southeast University Medical College https://orcid.org/0000-0001-7524-135X

Min Li

Southeast University Medical College

Jing Xie

Southeast University Medical College

Jing Gong

Southeast University Medical College

Naifeng Liu

Southeast University Medical College

\section{Research Article}

Keywords: A body shape index, Body mass index, Waist circumference, Abdominal aortic calcification

Posted Date: February 18th, 2022

DOl: https://doi.org/10.21203/rs.3.rs-812288/v1

License: (c) (i) This work is licensed under a Creative Commons Attribution 4.0 International License.

Read Full License 


\section{Abstract}

Background: The relationship between a body shape index (ABSI) and abdominal aortic calcification (AAC) is still unclear, so we tried to prove the relationship between ABSI and AAC in the general population free from cardiovascular disease.

Methods: The present study included 3140 participants aged 40-80 years from the 2013-2014 National Health and Nutrition Examination Survey. Logistic regression analysis and Receiver Operating Characteristic (ROC) curves were used to tested the association between ABSI and AAC.

Results: Participants with higher ABSI showed significantly higher proportion of AAC. Participants with higher $\mathrm{ABSI}$ had an increased risk of developing $A A C$ in the crude model (ABSI as a continuous variable: $\mathrm{OR}=2.485,95 \% \mathrm{Cl}: 2.099-2.942, P<0.001$; as a categorical variable: $\mathrm{OR}=2.132,95 \% \mathrm{Cl}: 1.826-2.489, P<$ 0.001), while higher $A B S I$ remained to be an independent risk predictor of AAC with the increase of confounding factors (all adjusted $P<0.05$ ). Further subgroup analyses showed that higher ABSI (regarding lower ABSI as reference) was consistently positively correlated with AAC in eleven subgroups, including sex, age, smoking history, hypertension, diabetes, sleep disorder, body mass index, systolic blood pressure, diastolic blood pressure, fasting plasma glucose and low-density lipoprotein cholesterol ( $P$ for interaction $>0.05$ ). However, in the osteoporosis and hemoglobin A1c subgroups, the correlation was no longer synchronized ( $P$ for interaction $<0.05$ ). The ROC curves analysis showed that the discriminant ability of ABSI was significantly higher than that of other models.

Conclusions: Independent of the related confounding factors, higher ABSI was significantly associated with higher prevalent AAC in the general population free from cardiovascular disease.

\section{Background}

Abdominal aortic calcification (AAC) refers to vascular calcification in the abdominal aorta, which has been proved by previous studies to be related to coronary artery calcification and the severity of cardiovascular disease (CVD)[1-3]. Calcium deposits may occur in all layers of blood vessels, including intima, media and adventitia[4,5]. The mechanism of vascular calcification has not been fully elucidated. It has been reported that chronic inflammation, insulin resistance, oxidative stress, vascular smooth muscle cell transdifferentiation, mitochondrial dysfunction, apoptosis, autophagy and DNA damage are involved in the occurrence of vascular calcification [4, 6-8]. And in clinical practice, it has been reported that advanced age, smoking, obesity, diabetes, dyslipidemia and low relative lean mass may be the risk factors of AAC[4, 9-12]. However, there may be other risk factors for AAC, such as nutritional and metabolic disorders. Further elucidation of other risk factors of AAC and targeted intervention are beneficial to prevent the occurrence and development of AAC, thereby reducing the occurrence of cardiovascular events.

For decades, with the improvement of living conditions, obesity, especially central obesity, has become an increasingly serious global health problem[13]. In contrast to subcutaneous fat, visceral fat accumulation 
has been shown to be closely associated with dyslipidemia, insulin resistance, diabetes and hypertension, all of which increase the risk of CVD[13-15]. Hence, it is of great significance to find a propagable and simple clinical tool for detecting visceral fat and diagnosing central obesity. As we expected, anthropometry just meets our requirements, that is, it is simple, cheap, non-invasive, and can be used for screening and early detection of obesity. At present, the traditional anthropometric indicators mainly include height, weight, body mass index (BMI), waist circumference (WC), hip circumference, Waist-toheight ratio (WHtR) and so on. However, previous studies have found that these indicators have some limitations, for instance, BMI can not reflect the fat distribution[14]. Although WC is generally considered to be a sign of central obesity, it still has some limitations, such as being disturbed by race and gender[16, 17]. Therefore, in order to overcome these limitations, Krakauer et al. developed a new nutritional index, namely a body shape index (ABSI), which is calculated from height, weight and WC[18]. And their study confirmed that ABSI was positively associated with visceral fat or central obesity, and they also found that the correlation between ABSI and premature death was higher than that of BMI and WC[18]. Since then, $A B S I$ has received more and more attention. Subsequent studies revealed the relationship between ABSI and arterial stiffness[19], carotid atherosclerosis[20], hypertension[21], metabolic syndrome[22], diabetes and CVD[23-27].

However, as far as we know, data about the correlation between ABSI and AAC is currently lacking. Furthermore, there are no related studies to compare the relative strength of predictive efficiency of traditional anthropometric indicators and ABSI for AAC. Therefore, the present study was to explore the relationship between $A B S I$ and $A A C$. Besides, we also tried to test the predictive ability of $A B S I$ and anthropometric indicators for AAC in the general population aged 40-80 years from the 2013-2014 National Health and Nutrition Examination Survey (NHANES 2013-2014).

\section{Methods}

\section{Study population}

NHANES is a regular survey of representative samples of the general population in the United States, which aimed to investigate the health and disease status of the general population in the United States and provide perfect health guidance, the contents and survey data of which have been described in detail in other literatures[28]. The present study included 3140 participants aged $40-80$ years from the NHANES 2013-2014. The study protocol of NHANES 2013-2014 was approved by the National Center for Health Statistics of the Center for Disease Control and Prevention Institutional Review Board, all participants of the present study provided written informed consent at the time of enrollment, and the study was consistent with the principles of the Declaration of Helsinki. Flow chart of participant selection of the present study was shown in the figure below (Fig. 1).

\section{Survey And Measurement}


After screening by inclusion and exclusion criteria, 3140 participants were enrolled in the present study. The demographic characteristics of all participants were obtained by standardized family interview questionnaire, including age, sex, race, smoking history, history of diabetes, hypertension, osteoporosis and sleep disorder. The race was divided into five groups: non-Hispanic White, non-Hispanic Black, Mexican American, other Hispanic and other races. Smoking history was divided into two groups: yes and no. Height, weight, systolic blood pressure (SBP), diastolic blood pressure (DBP) and WC were measured by medical trained professionals according to measurement procedures and standards, and the calculation method of the BMI was: weight $(\mathrm{kg})$ divided into the square of the height (meter), The WHtR was defined as the ratio of WC to height. The parameter values of blood samples of participants were determined strictly according to operational procedures by medically trained technicians in standard basic laboratory, including blood lipid profile, fasting plasma glucose (FPG), hemoglobin A1c (HbA1c), serum electrolytes, kidney function, etc.

For the calculation of $\mathrm{ABSI}$, we used the formula described by Krakauer et al. based on height, $\mathrm{BMI}$ and WC[18], that is:

$$
\text { ABSI }=\frac{\text { WC }}{\text { height }^{\frac{1}{2}} \mathrm{xBMI}^{\frac{2}{3}}}
$$

In our study, we divided participants into two groups based on the optimal cutoff point of ABSI: higher ABSI (>0.84; $n=1264)$ and lower ABSI ( $\leq 0.84 ; n=1876)$.

AAC was gained by transverse scanning of the lumbar spine (vertebrae L1-L4) with dual-energy X-ray absorptiometry (DXA) (Densitometer Discovery A, Hologic, Marlborough, MA, USA) and semi-quantified by the Kauppila score system, with scores ranging from 0 to 24, and the specific scoring rules of $A A C$ have been described in detail elsewhere[29,30]. We divided AAC into two groups: no calcification $(A A C=0)$ and calcification $(A A C>0)$.

\section{Statistical analysis}

All Statistical tests were performed with SPSS 19.0 (SPSS Inc., Chicago, Illinois, USA), MedCalc version 19.1 (MedCalc Software, Belgium) and R Programming Language (version 3.6.3). Continuous variables were expressed as mean \pm standard deviation or median (quartiles: Q1, Q3) depending on whether the data was normal distribution, and the independent-sample t-test or Mann-Whitney $\mathrm{U}$ test was used to examined the differences between the two groups. Categorical variables were presented as numbers (percentages), and Pearson chi-square test or Fisher's exact test was used to tested the differences between groups. The effect of ABSI on AAC was evaluated by the Logistic regression in different models, including crude model and adjusted models. Further subgroup analyses was performed to test the consistence of the predictive significance of ABSI for AAC according to sex, age ( $\leq 65$ and $>65$ years), smoking history, hypertension, diabetes, osteoporosis, sleep disorder, BMI ( $<23$ and $\geq 23 \mathrm{~kg} / \mathrm{m}^{2}$ ), SBP ( $<$ 140 and $\geq 140 \mathrm{mmHg}$ ), DBP ( $<90$ and $\geq 90 \mathrm{mmHg}$ ), FPG (<126 and $\geq 126 \mathrm{mg} / \mathrm{dL}), \mathrm{HbA} 1 \mathrm{c}(<6.5$ and $\geq$ 
$6.5 \%)$ and low-density lipoprotein cholesterol (LDL-C) ( $\leq 130$ and $>130 \mathrm{mg} / \mathrm{dL}$ ). The model used in the subgroup analyses did not contain other covariates. Besides, possible modifications of the connection between $A B S I$ and $A A C$ were also assessed by interaction tests. C-statistics derived from receiveroperating characteristic $(\mathrm{ROC})$ curve analysis were used to test the predictive potential of $A B S I$ and traditional anthropometric indicators for AAC, and examine the incremental effects of ABSI on the predictive potential of the baseline risk model that including traditional risk factors. DeLong's test was performed to compare the area under the curve (AUC) of each prediction model. The optimal cutoff point of $A B S I$ for predicting AAC were determine by ROC curve analysis. A two-tailed $P$ value $<0.05$ was regarded as statistically significant.

\section{Results}

The 3140 participants (median age: 58.0 years; $48.3 \%$ men) enrolled in the present study were divided into two groups based on the optimal cutoff point of $A B S I$ : higher $A B S I(>0.84 ; n=1264)$ and lower $A B S I$ $(\leq 0.84 ; n=1876)$. Baseline characteristics of total population and participants stratified by the ABSI of 0.84 were displayed in Table 1 and Fig. 2. Compared with participants in lower ABSI group, those with higher ABSI appeared to be older, display higher levels of WC, WHtR, SBP and AAC score, and higher percentage of male, Non-Hispanic white and smoker, and higher prevalence of diabetes, hypertension, osteoporosis, sleep disorder and AAC, while lower BMI. Laboratory indices including FPG, triglycerides (TG), blood urea nitrogen (BUN), uric acid, creatinine, HbA1c, $\gamma$-glutamyl transpeptidase (GGT) and alkaline phosphatase (ALP) were significantly higher in participants with higher ABSI, while total cholesterol (TC), LDL-C and high-density lipoprotein cholesterol (HDL-C) levels were comparatively lower. 
Table 1

Participants characteristics stratified by the optimal cutoff point of ABSI

\begin{tabular}{|c|c|c|c|c|}
\hline variables & $\begin{array}{l}\text { Total population } \\
(\mathrm{n}=3140)\end{array}$ & $\begin{array}{l}\text { Lower ABSI ( } \leq \\
0.84 ; \\
n=1876)\end{array}$ & $\begin{array}{l}\text { Higher ABSI (> } \\
0.84 ; \\
n=1264)\end{array}$ & $\begin{array}{l}P \\
\text { value }\end{array}$ \\
\hline Age, years & $58.0(48.0,68.0)$ & $53.0(46.0,63.0)$ & $64.0(56.0,73.0)$ & $\begin{array}{l}< \\
0.001\end{array}$ \\
\hline Sex, male, n (\%) & $1518(48.3)$ & $821(43.8)$ & $697(55.1)$ & $\begin{array}{l}< \\
0.001\end{array}$ \\
\hline Race, n (\%) & & & & $\begin{array}{l}< \\
0.001\end{array}$ \\
\hline Non-Hispanic white & $1375(43.8)$ & $724(38.6)$ & $651(51.5)$ & \\
\hline Non-Hispanic black & $620(19.7)$ & $439(23.4)$ & $181(14.3)$ & \\
\hline Mexican-American & $412(13.1)$ & $253(13.5)$ & $159(12.6)$ & \\
\hline Other Hispanic & $298(9.5)$ & $187(10.0)$ & $111(8.8)$ & \\
\hline Others & 435 (13.9) & $273(14.6)$ & $162(12.8)$ & \\
\hline Smoking history, n (\%) & $1452(46.2)$ & $765(40.8)$ & $687(54.4)$ & $\begin{array}{l}< \\
0.001\end{array}$ \\
\hline Diabetes, n (\%) & $648(20.6)$ & $290(15.5)$ & $358(28.3)$ & $\begin{array}{l}<.001 \\
0.001\end{array}$ \\
\hline Hypertension, n (\%) & $1486(47.3)$ & $782(41.7)$ & $704(55.7)$ & $\begin{array}{l}<.001 \\
0.001\end{array}$ \\
\hline Osteoporosis, n (\%) & $258(8.2)$ & $127(6.8)$ & $131(10.4)$ & $\begin{array}{l}< \\
0.001\end{array}$ \\
\hline Sleep disorder, n (\%) & $336(10.7)$ & $166(8.8)$ & $170(13.4)$ & $\begin{array}{l}< \\
0.001\end{array}$ \\
\hline Body mass index, $\mathrm{kg} / \mathrm{m}^{2}$ & $28.4 \pm 5.6$ & $28.8 \pm 5.8$ & $28.0 \pm 5.1$ & $\begin{array}{l}< \\
0.001\end{array}$ \\
\hline Waist circumference, $\mathrm{cm}$ & $99.3 \pm 13.6$ & $96.2 \pm 13.0$ & $103.9 \pm 13.0$ & $\begin{array}{l}< \\
0.001\end{array}$ \\
\hline WHtR & $0.6 \pm 0.1$ & $0.6 \pm 0.1$ & $0.6 \pm 0.1$ & $\begin{array}{l}< \\
0.001\end{array}$ \\
\hline $\mathrm{SBP}, \mathrm{mmHg}$ & $127.2 \pm 18.3$ & $125.1 \pm 17.1$ & $130.4 \pm 19.4$ & $\begin{array}{l}<.001 \\
0.001\end{array}$ \\
\hline
\end{tabular}

ABSI a body shape index, WHtR waist-to-height ratio, SBP systolic blood pressure, DBP diastolic blood pressure, LDL-C low-density lipoprotein cholesterol, HDL-C high-density lipoprotein cholesterol, FPG fasting plasma glucose, GGT Y-glutamyl transpeptidase, AAC abdominal aortic calcification 


\begin{tabular}{|c|c|c|c|c|}
\hline variables & $\begin{array}{l}\text { Total population } \\
(n=3140)\end{array}$ & $\begin{array}{l}\text { Lower ABSI ( } \leq \\
0.84 ; \\
n=1876)\end{array}$ & $\begin{array}{l}\text { Higher ABSI (> } \\
0.84 ; \\
n=1264)\end{array}$ & $\begin{array}{l}P \\
\text { value }\end{array}$ \\
\hline DBP, mmHg & $71.3 \pm 10.8$ & $72.0 \pm 10.2$ & $70.3 \pm 11.5$ & 0.221 \\
\hline \multicolumn{5}{|l|}{ Laboratory results } \\
\hline Triglycerides, mg/dL & $\begin{array}{l}132.0(86.0 \\
192.8)\end{array}$ & $\begin{array}{l}121.0(80.0 \\
176.0)\end{array}$ & $\begin{array}{l}144.0(97.0 \\
211.8)\end{array}$ & $<.001$ \\
\hline Total cholesterol, mg/dL & $196.0 \pm 42.7$ & $198.0 \pm 41.9$ & $193.2 \pm 43.7$ & 0.002 \\
\hline LDL-C, mg/dL & $114.8 \pm 36.0$ & $117.0 \pm 35.2$ & $111.4 \pm 37.1$ & 0.004 \\
\hline $\mathrm{HDL}-\mathrm{C}, \mathrm{mg} / \mathrm{dL}$ & $54.1 \pm 16.5$ & $55.6 \pm 16.9$ & $51.8 \pm 15.6$ & $<.001$ \\
\hline $\begin{array}{l}\text { Blood urea nitrogen, } \\
\mathrm{mg} / \mathrm{dL}\end{array}$ & $14.3 \pm 6.2$ & $13.6 \pm 5.3$ & $15.3 \pm 7.1$ & $<001$ \\
\hline Creatinine, mg/dL & $0.9(0.7,1.0)$ & $0.9(0.7,1.0)$ & $0.9(0.8,1.1)$ & $<.001$ \\
\hline Uric acid, mg/dL & $5.5 \pm 1.4$ & $5.3 \pm 1.3$ & $5.6 \pm 1.4$ & $\begin{array}{l}<.001 \\
0.01\end{array}$ \\
\hline $\mathrm{FPG}, \mathrm{mg} / \mathrm{dL}$ & $\begin{array}{l}98.0(90.0 \\
110.0)\end{array}$ & $96.0(89.0,109.0)$ & $\begin{array}{l}102.0(91.0 \\
119.0)\end{array}$ & $<.001$ \\
\hline Hemoglobin A1c, \% & $5.7(5.4,6.0)$ & $5.6(5.3,5.9)$ & $5.8(5.4,6.2)$ & $<001$ \\
\hline Total bilirubin, mg/dL & $0.6 \pm 0.3$ & $0.6 \pm 0.3$ & $0.6 \pm 0.3$ & 0.663 \\
\hline GGT, U/L & $21.0(15.0,30.0)$ & $20.0(14.0,30.0)$ & $21.0(15.0,31.0)$ & 0.002 \\
\hline $\begin{array}{l}\text { Alkaline phosphatase, } \\
\text { IU/L }\end{array}$ & $65.0(53.0,77.0)$ & $64.0(53.0,75.0)$ & $67.0(54.0,80.0)$ & $<001$ \\
\hline Total calcium, mg/dL & $9.5 \pm 0.4$ & $9.4 \pm 0.4$ & $9.5 \pm 0.3$ & 0.226 \\
\hline Phosphorus, mg/dL & $3.8 \pm 0.6$ & $3.8 \pm 0.6$ & $3.8 \pm 0.6$ & 0.164 \\
\hline 25-OH-VitD3, nmol/L & $63.8(45.9,81.0)$ & $63.3(46.2,79.6)$ & $64.9(45.7,83.1)$ & 0.065 \\
\hline AAC, n (\%) & $947(30.2)$ & $444(23.7)$ & $503(39.8)$ & $<.001$ \\
\hline $\begin{array}{l}\text { ABSI a body shape index, } \\
\text { pressure, LDL-C low-dens } \\
\text { fasting plasma glucose, }\end{array}$ & $\begin{array}{l}\text { HtR waist-to-heigl } \\
\text { ipoprotein choles } \\
\text { ry-glutamyl trans }\end{array}$ & $\begin{array}{l}\text { atio, SBP systolic } \\
\text { ol, HDL-C high-der } \\
\text { ptidase, AAC abdo }\end{array}$ & $\begin{array}{l}\text { od pressure, DBP } \\
\text { y lipoprotein chol } \\
\text { nal aortic calcific }\end{array}$ & $\begin{array}{l}\text { c blood } \\
\text { FPG }\end{array}$ \\
\hline
\end{tabular}

In Logistic regression analysis, four models (crude model and Model 1-3) including covariables with statistically significance $(P<0.1)$ and clinical significance were established to assess the predictive 
significance of $A B S I$ for AAC. With the increase of confounding factors, the risk of participants with higher $\mathrm{ABSI}$ developing into AAC gradually decreased, while higher $\mathrm{ABSI}$ remained to be an independent risk predictor of $\mathrm{AAC}$, whether $\mathrm{ABSI}$ was regarded as a categorical or continuous variable (all $P<0.05$ in Model 1-3) (Table 2). Further subgroup analyses was performed to test the consistence of the predictive significance of $A B S I$ for $A A C$ (thirteen subgroups as mentioned above) (Fig. 3). The higher ABSI (regarding lower ABSI as reference) was consistently positively correlated with AAC in eleven subgroups, including sex, age, smoking history, hypertension, diabetes, sleep disorder, BMI, SBP, DBP, FPG and LDL-C ( $P$ for interaction $>0.05$ ). However, in the osteoporosis and HbA1c subgroups, the correlation between the two was no longer synchronized $(P$ for interaction $<0.05)$. Interestingly, the risk of participants with higher ABSI developing into AAC seemed to be more noticeable in participants without osteoporosis [OR (95\% $\mathrm{Cl})$ without osteoporosis 2.157 (1.829-2.542) vs. with osteoporosis $1.504(0.920-2.459), P$ for interaction $<0.001$ ] and with $\mathrm{HbA} 1 \mathrm{c}<6.5 \%$ [OR $(95 \% \mathrm{Cl}) \mathrm{HbA} 1 \mathrm{c}<6.5 \% 2.251$ (1.898-2.669) vs. HbA1c $\geq$ $6.5 \% 1.297(0.881-1.910), P$ for interaction $=0.011]$.

Table 2

Predictive value of $A B S I$ for $A A C$ in different logistic regression models

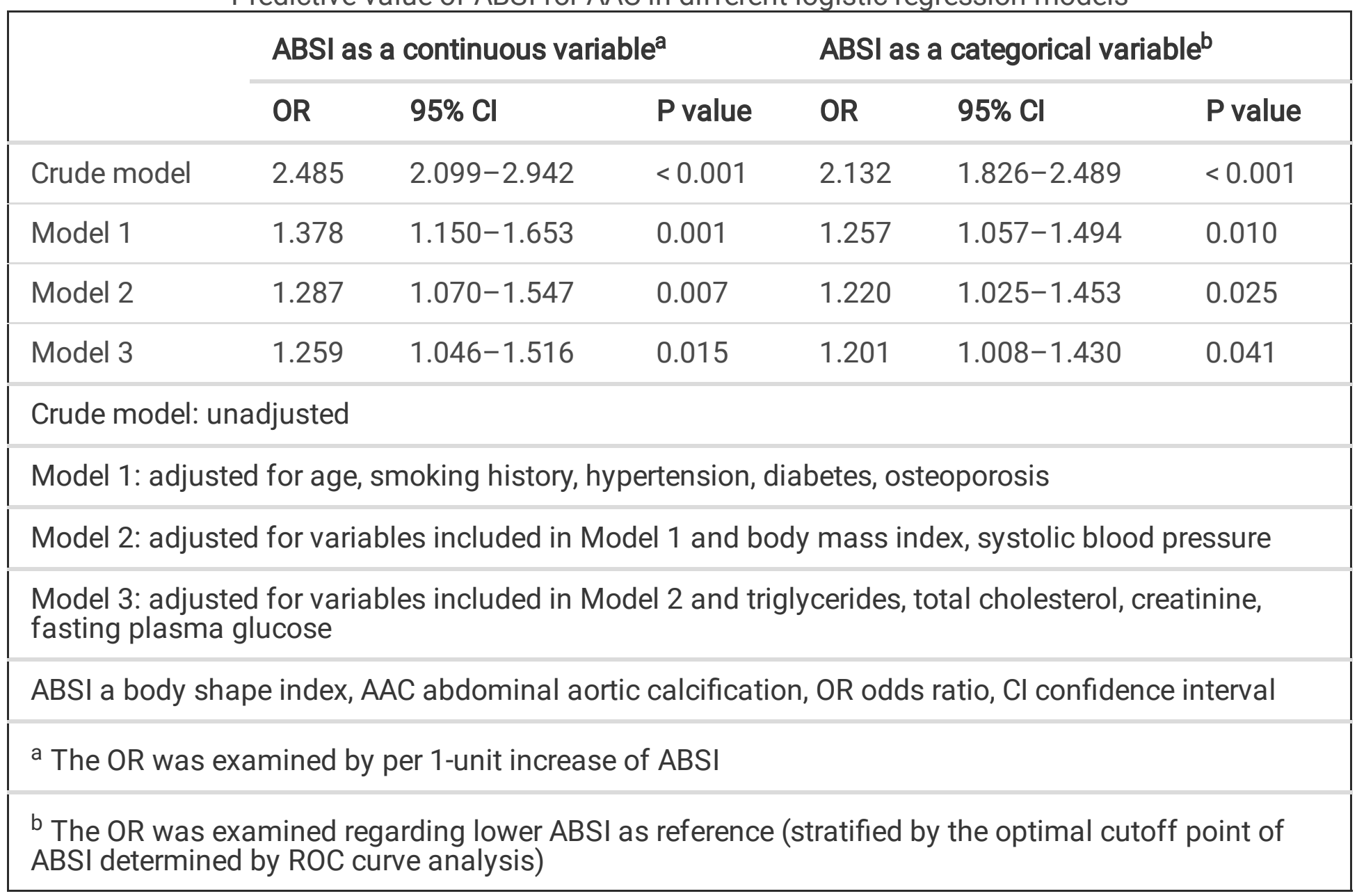

The comparative analysis of AUC of different models for predicting AAC showed that the discriminant ability of $A B S I$ was significantly higher than that of other univariate predictive models, including height, weight, BMI, WC and WHtR (all $P$ for comparison $<0.001$ ). However, the addition of ABSI had no significant increasing effect on the AUC obtained by the baseline risk model composed of age, smoking 
history, diabetes, hypertension, osteoporosis, SBP, TG, TC, FPG, HbA1c, creatinine, uric acid, ALP, total calcium and 25-OH-VitD3 (AUC: baseline risk model, 0.726 vs. baseline risk model $+\mathrm{ABSI}, 0.728, P$ for comparison $=0.098)($ Table 3, Fig. 4).

Table 3

C-statistics for discrimination ability of different models

\begin{tabular}{|c|c|c|c|c|c|}
\hline variables & AUC & $95 \% \mathrm{Cl}$ & $\begin{array}{l}P \\
\text { value }\end{array}$ & $Z$ value & $\begin{array}{l}\text { Pfor } \\
\text { comparison }\end{array}$ \\
\hline \multicolumn{6}{|l|}{ Univariate model } \\
\hline ABSI & 0.625 & $\begin{array}{l}0.608- \\
0.642\end{array}$ & $<.001$ & Reference & Reference \\
\hline Height & 0.532 & $\begin{array}{l}0.514- \\
0.549\end{array}$ & 0.005 & 5.710 & $<0.001$ \\
\hline Weight & 0.562 & $\begin{array}{l}0.545- \\
0.580\end{array}$ & $<.001$ & 4.217 & $<0.001$ \\
\hline BMI & 0.548 & $\begin{array}{l}0.530- \\
0.565\end{array}$ & $<.001$ & 5.385 & $<0.001$ \\
\hline WC & 0.505 & $\begin{array}{l}0.487- \\
0.523\end{array}$ & 0.652 & 6.841 & $<0.001$ \\
\hline WHtR & 0.512 & $\begin{array}{l}0.494- \\
0.529\end{array}$ & 0.284 & 8.687 & $<0.001$ \\
\hline \multicolumn{6}{|l|}{ Combined variable model } \\
\hline $\begin{array}{l}\text { Baseline risk model }{ }^{\mathrm{a}} \text { without } \\
\text { ABSI }\end{array}$ & 0.726 & $\begin{array}{l}0.710- \\
0.741\end{array}$ & $<001$ & Reference & Reference \\
\hline Baseline risk model $^{\mathrm{a}}$ with $\mathrm{ABSI}$ & 0.728 & $\begin{array}{l}0.712- \\
0.744\end{array}$ & $<.001$ & 1.657 & 0.098 \\
\hline \multicolumn{6}{|c|}{$\begin{array}{l}\text { ABSI a body shape index, BMI body mass index, WC waist circumference, WHtR Waist-to-height ratio, } \\
\text { AUC area under the curve, Cl confidence interval }\end{array}$} \\
\hline \multicolumn{6}{|c|}{$\begin{array}{l}\text { a The baseline risk model included age, smoking history, diabetes, hypertension, osteoporosis, systolic } \\
\text { blood pressure, triglycerides, total cholesterol, fasting plasma glucose, hemoglobin A1c, creatinine, } \\
\text { uric acid, alkaline phosphatase, total calcium and } 25-\mathrm{OH}-\mathrm{VitD} 3\end{array}$} \\
\hline
\end{tabular}

\section{Discussion}

As far as we know, the present study was the first report on the relationship between ABSI and AAC. In the present study, we retrospectively explored the predictive importance of $A B S I$ derived from traditional anthropometric indicators for AAC. The main findings were as follows: (1) compared with participants in lower $A B S I$ group, those with higher $A B S I$ showed higher levels of $A A C$ score and higher prevalence of $A A C$; (2) the higher $A B S I$ ( per 1-unit increase or regarding lower $A B S I$ as reference) was a strong 
independent risk predictor of AAC in our population, although after adjusting for possible interference factors; (3) the risk of participants with higher ABSI developing into AAC seemed to be more noticeable in participants without osteoporosis and with $\mathrm{HbA1c}<6.5 \%$; (4) the discriminant ability of ABSI for predicting AAC was significantly higher than that of other anthropometric indicators. These results suggest that $A B S I$ may be essential for risk management of AAC.

AAC has been widely considered as an important risk factor for CVD, and it is very common in patients with CVD. Some studies have shown that AAC is significantly associated with incident myocardial infarction[2], stroke[31], osteoporosis[32], fracture[33], CVD mortality[2], all-cause mortality[3], etc. Therefore, for these patients, the identification of pathogenic factors of AAC is of great clinical significance for primary and secondary prevention of CVD. It has been reported that advanced age, smoking, diabetes, obesity and dyslipidemia may be the risk factors of AAC $[4,9-11]$. However, there may be other risk factors for AAC, such as nutrition indices.

At present, $\mathrm{BMI}$ and $\mathrm{WC}$ are the most commonly used anthropometric indicators in clinical practice, but both of them have some limitations in fat distribution. First, BMI can't not only distinguish adipose tissue from non-adipose tissue, but also can't reflect fat distribution[34]. In fact, people with excess visceral fat or central obesity are more likely to develop CVD and metabolic syndrome[14, 15]. Unlike BMI, WC has always been regarded as an alternative indicator of central obesity[35]. Previous studies have shown that WC could predict the risk of death better than BMI[36,37], but a comparative study showed that WC was weakly or negatively correlated with subclinical CVD[19]. This suggests that the ability of WC to predict metabolic-related diseases may be overrated. The reason for this may be that the WC can't distinguish between subcutaneous fat and visceral fat, and can't reflect the difference of height and race[17]. Therefore, the WC may not be enough to fully represent central obesity. In addition, although the WHtR derived from WC and height has also been shown to predict metabolic disorders[38], it can't reflect differences of weight between individuals. Therefore, it is essential to develop a better tool to assess central obesity. It is reported that imaging technology is the gold standard for the evaluation of central obesity, but it is difficult to be widely popularized because of its high cost, complex operation and radiation. Therefore, a simple evaluation method comes into being, that is, ABSI developed by Krakauer et al. in 2012[18].

$A B S I$ is a recently developed nutritional index composed of height, weight and WC, which is reported to be positively correlated with central obesity, metabolic related diseases and death risks[18, 22]. A

subsequent study found that among teenagers, ABSI was better at identifying hypertension than $\mathrm{BMI}$ and WC[39]. And in Chinese adults, ABIS was a better predictor of diabetes and metabolic syndrome than BMI and WC[25]. Recent studies have also found that ABSI had a stronger correlation with all-cause mortality and CVD mortality than WC, BMI and WHtR, and it might be an important marker of atherosclerosis in patients with type 2 diabetes[40,41]. Similarly, studies by Geraci et al. have also shown that ABSI might be considered as a better predictor of carotid atherosclerosis in patients with hypertension than traditional nutrition indexes, including WC and BMI[20]. However, some studies have found that ABSI is not superior to BMI and WC in predicting the risk of related disease or death. For example, two studies 
coincidentally found that in Chinese children, adolescents or adults and the elderly, the correlation between $\mathrm{ABSI}$ and pre-hypertension or hypertension was not higher than WC, BMI and WHtR, while the WHtR had the highest predictive power[21, 42]. In addition, another study found that although ABSI was positively correlated with arterial stiffness, its AUC value was significantly lower than that of WHtR in differentiating arterial stiffness, suggesting that ABSI might not be a better predictor of arterial stiffness in Chinese population[19]. Besides, A large European cohort study found that WC, BMI and WHtR were Jshaped correlated with all-cause mortality, while ABSI was positively correlated with all-cause mortality, and BMI was superior to ABSI in predicting CVD mortality[43]. Furthermore, a meta-analysis of 30 clinical studies showed that higher ABSI was associated with increased risk of hypertension, type 2 diabetes, CVD and all-cause death, which increased by $13 \%, 35 \%, 21 \%$ and $55 \%$, respectively, and ABSI was superior to WC and BMI in predicting all-cause mortality, but performed poorly in predicting chronic diseases[23]. However, the studies mentioned above are aimed at exploring the relationship between ABSI and other diseases, and there is little evidence to compare ABSI with other anthropometric indicators in predicting the risk of AAC. Our research was the first to determine the ability of ABSI to recognize AAC. The results showed that there was a positive correlation between ABSI and AAC. Additionally, we found that $A B S I$ was a better indicator of $A A C$ than $B M I, W C$ and WHtR, and it showed similar predictive power to baseline risk models including age, smoking history, diabetes, hypertension, osteoporosis, SBP, TG, TC, FPG, HbA1c, creatinine, uric acid, ALP, total calcium and 25-OH-VitD3 in the American population.

Moreover, we also found for the first time that participants with higher ABSI had a higher risk of developing $\mathrm{AAC}$ in the $\mathrm{HbA} 1 \mathrm{c}<6.5 \%$ and non-osteoporosis subgroups. The reason for this might be that osteoporosis and $\mathrm{HbA} 1 \mathrm{c} \geq 6.5$ were the interference factors of $\mathrm{ABSI}$ risk prediction model, which was also the focus of our future research. The homogenization and differentiation of the above studies may be explained by the differences in race, sample size and population characteristics.

Innovatively, our findings added to the evidence of ABSI and CVD from clinical to subclinical diseases. Moreover, we compared the predictive value of $A B S I$ and other nutrition indexes for AAC for the first time. Therefore, this study provided additional information that the evaluation of ABSI might be of clinical significance in primary prevention to identify people at risk of CVD. In spite of this, several limitations still existed in this study. Firstly, the present study was a cross-sectional study, which could not identify the causal relationship between ABSI and AAC. Secondly, in Logistic regression analysis, we only controlled

for several meaningful confounding factors, but there might be other confounding factors not included in our study, such as inflammatory indicators. Thirdly, ABSI with a very small variance was highly concentrated around the mean value, which made it difficult to define the best critical value of ABSI in clinical practice. Finally, The data of this study only came from the general population of NHANES 20132014 , so the findings may not be applicable more populations broadly.

\section{Conclusions}

Taken together, our results showed that WC, BMI, WHtR and ABSI were significantly associated with AAC, and found that $A B S I$ was an independent predictor of $A A C$. Furthermore, $A B S I$ was superior to $B M I, W C$ 
and WHtR in predicting the risk of AAC in our study. However, whether ABSI is suitable for clinical practice needed to be further studied in different populations.

\section{Abbreviations}

ABSI: A body shape index; AAC: Abdominal aortic calcification; ROC: Receiver operating characteristic; CVD: Cardiovascular disease; BMI: Body mass index; WC: Waist circumference; WHtR: Waist-to-height ratio; NHANES 2013-2014: 2013-2014 National Health and Nutrition Examination Survey; SBP: Systolic blood pressure; DBP: Diastolic blood pressure; FPG: Fasting plasma glucose; HbA1c: Hemoglobin A1c; DXA: Dual-energy X-ray absorptiometry; LDL-C: Low-density lipoprotein cholesterol; AUC: Area under the curve; TG: Triglycerides; BUN: Blood urea nitrogen; GGT: $\gamma$-glutamyl transpeptidase: ALP: Alkaline phosphatase; TC: Total cholesterol; HDL-C: high-density lipoprotein cholesterol; OR: odds ratio; Cl: confidence interval.

\section{Declarations}

\section{Acknowledgements}

This work thanks the other investigators, the staff, and the participants of the NHANES 2013-2014 study for their valuable contributions.

\section{Authors' contributions}

ZWW collected, analyzed and interpreted the data and drafted the manuscript; ML, JX and JG revised the manuscript; NFL was the designer of the manuscript and approved to submit the manuscript finally. All authors read and approved the final version of the manuscript.

\section{Funding}

This work was supported by the National Nature Science Foundation of China [Grant No. 81770451].

\section{Availability of data and materials}

The NHANES database is available at: https://www.cdc.gov/nchs/nhanes/about_nhanes.htm. The datasets used and/or analyzed during the current study are available from the corresponding author on reasonable request.

\section{Ethics approval and consent to participate}

The study of NHANES 2013-2014 was approved by the National Center for Health Statistics of the Center for Disease Control and Prevention Institutional Review Board. Informed consent was obtained from all participants included in the study. 


\section{Consent for publication}

Not applicable.

\section{Competing interests}

The authors declare no conflict of interest.

\section{Author details}

${ }^{1}$ Department of Cardiology, Zhongda Hospital, School of Medicine, Southeast University, Nanjing 210009, Jiangsu, China. ${ }^{2}$ College of Basic Medicine and Clinical Pharmacy, China Pharmaceutical University, Nanjing 210000, Jiangsu, China.

\section{References}

1. Schousboe JT, Claflin D, Barrett-Connor E. Association of Coronary Aortic Calcium With Abdominal Aortic Calcium Detected on Lateral Dual Energy X-Ray Absorptiometry Spine Images. Am J Cardiol. 2009;104(3):299-304.

2. Criqui MH, Denenberg JO, McClelland RL, Allison MA, Ix JH, Guerci A, Cohoon KP, Srikanthan P, Watson KE, Wong ND. Abdominal Aortic Calcium, Coronary Artery Calcium, and Cardiovascular Morbidity and Mortality in the Multi-Ethnic Study of Atherosclerosis. Arterioscler Thromb Vasc Biol. 2014;34(7):1574-9.

3. Wilson PW, Kauppila LI, O'Donnell CJ, Kiel DP, Hannan M, Polak JM, Cupples LA. Abdominal aortic calcific deposits are an important predictor of vascular morbidity and mortality. Circulation. 2001;103(11):1529-34.

4. Golledge J. Abdominal aortic calcification: clinical significance, mechanisms and therapies. Curr Pharm Des. 2014;20(37):5834-8.

5. Szulc P. Abdominal aortic calcification: A reappraisal of epidemiological and pathophysiological data. BONE. 2016;84:25-37.

6. Leopold JA. Vascular calcification: Mechanisms of vascular smooth muscle cell calcification. Trends Cardiovasc Med. 2015;25(4):267 - 74.

7. Phadwal K, Vrahnas C, Ganley IG, MacRae VE. Mitochondrial Dysfunction: Cause or Consequence of Vascular Calcification? Front Cell Dev Biol. 2021;9:611922.

8. Li M, Zhu Y, Jaiswal SK, Liu N. Mitochondria Homeostasis and Vascular Medial Calcification. Calcif Tissue Int. 2021;109(2):113 - 20.

9. Yang $\mathrm{S}$, Yang $\mathrm{H}$, Chen $\mathrm{Y}$, Chen $\mathrm{W}$. Unraveling the link between metabolic syndrome and abdominal aortic calcification. Nutr Metab Cardiovasc Dis. 2021;31(2):464 - 71.

10. Yuan M, Hsu F, Bowden DW, Xu J, Carrie Smith S, Wagenknecht LE, Comeau ME, Divers J, Register TC, Jeffrey Carr J, et al. Relationships between measures of adiposity with subclinical 
atherosclerosis in patients with type 2 diabetes. Obesity (Silver Spring). 2016;24(8):1810-8.

11. Bendix EF, Johansen E, Ringgaard T, Wolder M, Starup-Linde J. Diabetes and Abdominal Aortic Calcification-a Systematic Review. Curr Osteoporos Rep. 2018;16(1):42-57.

12. Rodríguez AJ, Scott D, Khan B, Khan N, Hodge A, English DR, Giles GG, Ebeling PR. Low Relative Lean Mass is Associated with Increased Likelihood of Abdominal Aortic Calcification in CommunityDwelling Older Australians. Calcif Tissue Int. 2016;99(4):340-9.

13. Bray GA, Heisel WE, Afshin A, Jensen MD, Dietz WH, Long M, Kushner RF, Daniels SR, Wadden TA, Tsai AG, et al. The Science of Obesity Management: An Endocrine Society Scientific Statement. Endocr Rev. 2018;39(2):79-132.

14. Fox CS, Massaro JM, Hoffmann U, Pou KM, Maurovich-Horvat P, Liu CY, Vasan RS, Murabito JM, Meigs JB, Cupples LA, et al. Abdominal visceral and subcutaneous adipose tissue compartments: association with metabolic risk factors in the Framingham Heart Study. Circulation. 2007;116(1):3948.

15. Britton KA, Massaro JM, Murabito JM, Kreger BE, Hoffmann U, Fox CS. Body fat distribution, incident cardiovascular disease, cancer, and all-cause mortality. J Am Coll Cardiol. 2013;62(10):921-5.

16. Zhou BF, Cooperative Meta-Analysis Group of the Working Group on Obesity in China. Predictive values of body mass index and waist circumference for risk factors of certain related diseases in Chinese adults-study on optimal cut-off points of body mass index and waist circumference in Chinese adults. Biomed Environ Sci. 2002;15(1):83-96.

17. Misra A, Wasir JS, Vikram NK. Waist circumference criteria for the diagnosis of abdominal obesity are not applicable uniformly to all populations and ethnic groups. Nutrition. 2005;21(9):969 - 76.

18. Krakauer NY, Krakauer JC. A new body shape index predicts mortality hazard independently of body mass index. PLoS One. 2012;7(7):e39504.

19. Zhang J, Fang L, Qiu L, Huang L, Zhu W, Yu Y. Comparison of the ability to identify arterial stiffness between two new anthropometric indices and classical obesity indices in Chinese adults. Atherosclerosis. 2017;263:263 - 71.

20. Geraci G, Zammuto M, Gaetani R, Mattina A, D'Ignoto F, Geraci C, Noto D, Averna M, Cottone S, Mulè G. Relationship of a Body Shape Index and Body Roundness Index with carotid atherosclerosis in arterial hypertension. Nutr Metab Cardiovasc Dis. 2019;29(8):822-9.

21. Hu L, Hu G, Huang X, Zhou W, You C, Li J, Li P, Wu Y, Wu Q, Wang Z, et al. Different adiposity indices and their associations with hypertension among Chinese population from Jiangxi province. $B M C$ Cardiovasc Disord. 2020;20(1):115.

22. Wu L, Zhu W, Qiao Q, Huang L, Li Y, Chen L. Novel and traditional anthropometric indices for identifying metabolic syndrome in non-overweight/obese adults. Nutr Metab (Lond). 2021;18(1):3.

23. Ji M, Zhang S, An R. Effectiveness of A Body Shape Index (ABSI) in predicting chronic diseases and mortality: a systematic review and meta-analysis. Obes Rev. 2018;19(5): 737 - 59.

24. Zhao Q, Zhang K, Li Y, Zhen Q, Shi J, Yu Y, Tao Y, Cheng Y, Liu Y. Capacity of a body shape index and body roundness index to identify diabetes mellitus in Han Chinese people in Northeast China: a 
cross-sectional study. Diabet Med. 2018;35(11):1580-7.

25. Wei J, Liu X, Xue H, Wang Y, Shi Z. Comparisons of Visceral Adiposity Index, Body Shape Index, Body Mass Index and Waist Circumference and Their Associations with Diabetes Mellitus in Adults. Nutrients. 2019;11(7):1580.

26. Cho H, Chung W, Moon S, Ryu O, Kim MK, Kang JG. Effect of Sarcopenia and Body Shape on Cardiovascular Disease According to Obesity Phenotypes. Diabetes Metab J. 2021;45(2):209-218.

27. Tang J, Zhao S, Yu S, Chi C, Ji H, Xiong J, Teliewubai J, Fan X, Maimaitiaili R, Xu Y, et al. Association between hypertension-mediated organ damage and obesity defined by novel anthropometric indices in community-dwelling elderly individuals. Clin Nutr. 2021;40(6):4473-80.

28. Burt VL, Harris T. The third National Health and Nutrition Examination Survey: contributing data on aging and health. Gerontologist. 1994;34(4):486 - 90.

29. Kauppila LI, Polak JF, Cupples LA, Hannan MT, Kiel DP, Wilson PW. New indices to classify location, severity and progression of calcific lesions in the abdominal aorta: a 25-year follow-up study. Atherosclerosis. 1997; 132(2):245 - 50.

30. Schousboe JT, Wilson KE, Kiel DP. Detection of Abdominal Aortic Calcification With Lateral Spine Imaging Using DXA. J Clin Densitom. 2006;9(3):302-8.

31. Hollander M, Hak AE, Koudstaal PJ, Bots ML, Grobbee DE, Hofman A, Witteman JC, Breteler MM. Comparison between measures of atherosclerosis and risk of stroke: the Rotterdam Study. Stroke. 2003;34(10):2367-72.

32. Zhou R, Zhou H, Cui M, Wang Y, Tan J, Sawmiller D, Xu J. Association Between Aortic Calcification and the Risk of Osteoporosis in a Chinese Cohort: The Chongqing Osteoporosis Study. Calcif Tissue Int. 2013;93(5):419 - 25.

33. Szulc P, Blackwell T, Kiel DP, Schousboe JT, Cauley J, Hillier T, Hochberg M, Rodondi N, Taylor BC, Black $D$, et al. Abdominal aortic calcification and risk of fracture among older women - The SOF study. Bone. 2015;81:16-23.

34. Nevill AM, Stewart AD, Olds T, Holder R. Relationship between adiposity and body size reveals limitations of BMI. Am J Phys Anthropol. 2006;129(1):151-6.

35. Balkau B, Deanfield JE, Després JP, Bassand JP, Fox KA, Smith SC Jr, Barter P, Tan CE, Van Gaal L, Wittchen $\mathrm{HU}$, et al. International Day for the Evaluation of Abdominal Obesity (IDEA) A Study of Waist Circumference, Cardiovascular Disease, and Diabetes Mellitus in 168000 Primary Care Patients in 63 Countries. Circulation. 2007;116(17): 1942-51.

36. Pischon T, Boeing H, Hoffmann K, Bergmann M, Schulze MB, Overvad K, van der Schouw YT, Spencer E, Moons KG, Tjonneland A, et al. General and abdominal adiposity and risk of death in Europe. $N$ Engl J Med. 2008;359(20):2105-20.

37. Seidell JC. Waist circumference and waist/hip ratio in relation to all-cause mortality, cancer and sleep apnea. Eur J Clin Nutr. 2010;64(1):35-41.

38. Zhu Q, Shen F, Ye T, Zhou Q, Deng H, Gu X. Waist-to-height ratio is an appropriate index for identifying cardiometabolic risk in Chinese individuals with normal body mass index and waist circumference. $J$ 
Diabetes. 2014;6(6):527 - 34.

39. Duncan MJ, Mota J, Vale S, Santos MP, Ribeiro JC. Associations between body mass index, waist circumference and body shape index with resting blood pressure in Portuguese adolescents. Ann Hum Biol. 2013;40(2):163-7.

40. Bouchi R, Asakawa M, Ohara N, Nakano Y, Takeuchi T, Murakami M, Sasahara Y, Numasawa M, Minami I, Izumiyama $\mathrm{H}$, et al. Indirect measure of visceral adiposity 'A Body Shape Index' (ABSI) is associated with arterial stiffness in patients with type 2 diabetes. BMJ Open Diabetes Res Care. 2016;4(1):e000188.

41. Dhana K, Kavousi M, Ikram MA, Tiemeier HW, Hofman A, Franco OH. Body shape index in comparison with other anthropometric measures in prediction of total and cause-specific mortality. $J$ Epidemiol Community Health. 2016;70(1):90 - 6.

42. Tong Y, Han E. Associations between body shape, body adiposity and other indices: a case study of hypertension in Chinese children and adolescents. Ann Hum Biol. 2019;46(6):460-6.

43. Song X, Jousilahti P, Stehouwer CDA, Söderberg S, Onat A, Laatikainen T, Yudkin JS, Dankner R, Morris R, Tuomilehto $\mathrm{J}$, et al. Cardiovascular and all-cause mortality in relation to various anthropometric measures of obesity in Europeans. Nutr Metab Cardiovasc Dis. 2015;25(3):295-304.

\section{Figures}

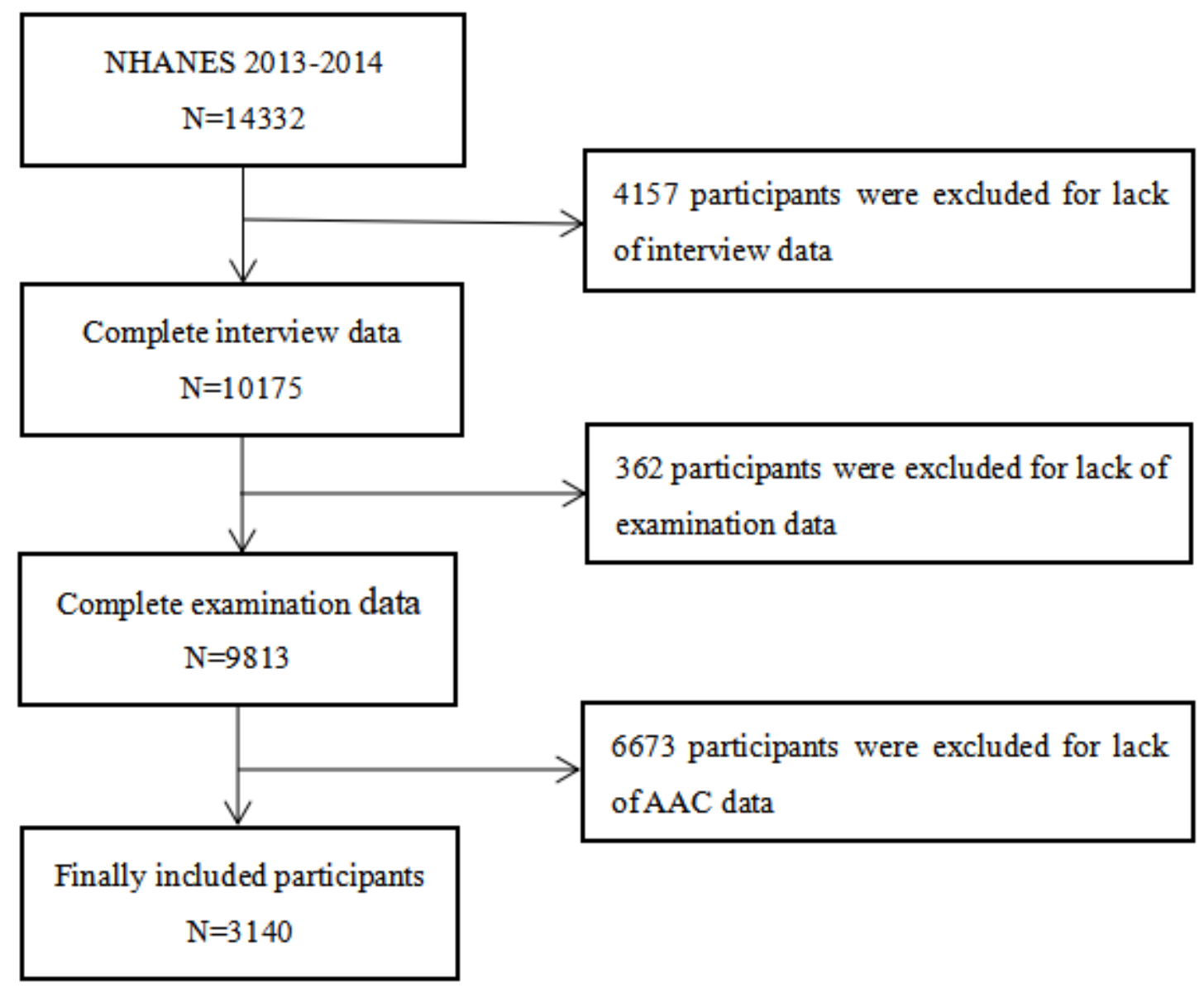


Figure 1

Flow chart of the study population enrollment

NHANES 2013-2014 2013-2014 National Health and Nutrition Examination Survey, AAC abdominal aortic calcification

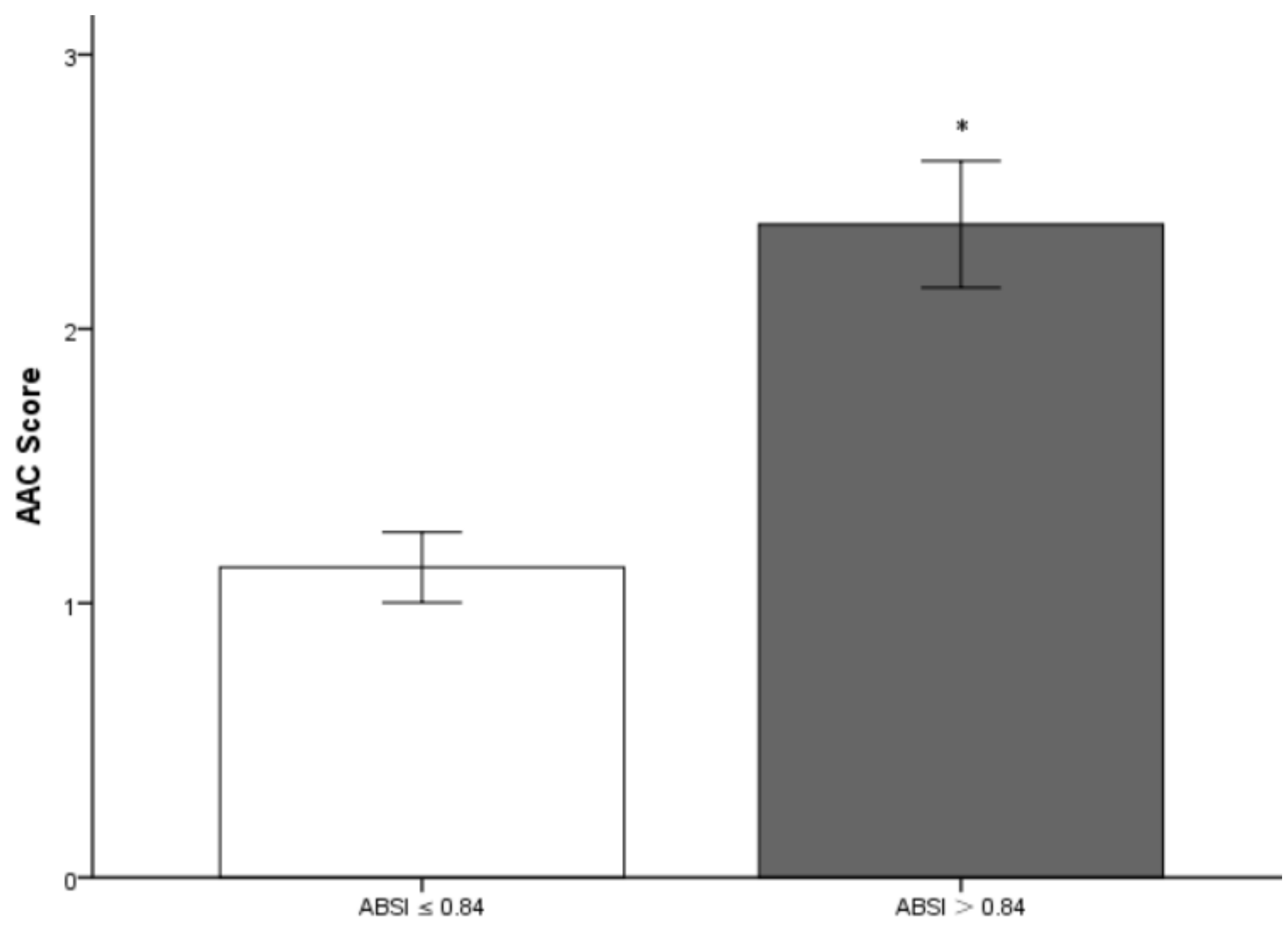

Figure 2

Bar graph of mean value of AAC Score stratified by a body shape index (ABSI)

AAC abdominal aortic calcification

* Compared with lower ABSI group, participants in higher ABSI group had significantly higher AAC Score $(P<0.001)$ 
Subgroups

Sex (Male)

Sex (Female)

Age $\leq 65$ years

Age $>65$ years

Smoking history -

Smoking history +

Hypertension -

Hypertension +

Diabetes -

Diabetes +

Osteoporosis -

Osteoporosis +

Sleep disorder -

Sleep disorder +

$\mathrm{BMl}<23 \mathrm{~kg} / \mathrm{m}^{\wedge} 2$

$\mathrm{BMI} \geq 23 \mathrm{~kg} / \mathrm{m}^{\wedge} 2$

SBP $<140 \mathrm{mmHg}$

$\mathrm{SBP} \geq 140 \mathrm{mmHg}$

DBP $<90 \mathrm{mmHg}$

$\mathrm{DBP} \geq 90 \mathrm{mmHg}$

$\mathrm{FPG}<126 \mathrm{mg} / \mathrm{dL}$

$\mathrm{FPG} \geq 126 \mathrm{mg} / \mathrm{dL}$

$\mathrm{HbA} 1 \mathrm{c}<6.5 \%$

$\mathrm{HbA} 1 \mathrm{c} \geq 6.5 \%$

$\mathrm{LDL}-\mathrm{C} \leq 130 \mathrm{mg} / \mathrm{dL}$

LDL-C > $130 \mathrm{mg} / \mathrm{dL}$
OR $(95 \% \mathrm{Cl})$

$2.213(1.773-2.761)$

2.050 (1.645-2.555)

$P$ value

$P$ for interaction

$1.632(1.318-2.022)<0.001$

$1.503(1.158-1.951) \quad 0.002$

$2.231(1.783-2.792)<0.001$

$1.877(1.510-2.334)<0.001$

0.278

$1.881(1.485-2.383)<0.001$

$2.038(1.649-2.519)<0.001$

0.621

$2.135(1.786-2.552)<0.001$

$1.793(1.294-2.484)<0.001$

0.357

$2.157(1.829-2.542) \quad<0.001$

$1.504(0.920-2.459) \quad 0.103$

$<0.001$

$2.133(1.809-2.514)<0.001$

$2.204(1.356-3.582) \quad 0.001$

0.165

$3.410(2.093-5.557)<0.001$

$2.019(1.714-2.379)<0.001$

0.215

$2.033(1.697-2.436)<0.001$

$2.033(1.488-2.778)<0.001$

0.999

$2.080(1.775-2.437)<0.001$

$4.184(1.883-9.298)<0.001$

0.09

$2.133(1.797-2.531)<0.001$

$1.720(1.177-2.515) \quad 0.005$

0.439

$2.251(1.898-2.669) \quad<0.001$

$1.297(0.881-1.910) \quad 0.188$

0.011

$2.608(1.995-3.411)<0.001$

$1.981(1.315-2.986) \quad 0.001$

0.272

\section{Figure 3}

Logistic regression analysis evaluating predictive implication of $A B S I$ in different subgroups. The OR was examined regarding lower $\mathrm{ABSI}$ as reference (stratified by the optimal cutoff point of ABSI determined by ROC curve analysis)

ABSIa body shape index, $B M I$ body mass index, SBP systolic blood pressure, DBP diastolic blood pressure, FPG fasting plasma glucose, $H b A 1 c$ hemoglobin A1c, $L D L-C$ low-density lipoprotein cholesterol, OR odds ratio, $\mathrm{Cl}$ confidence interval 

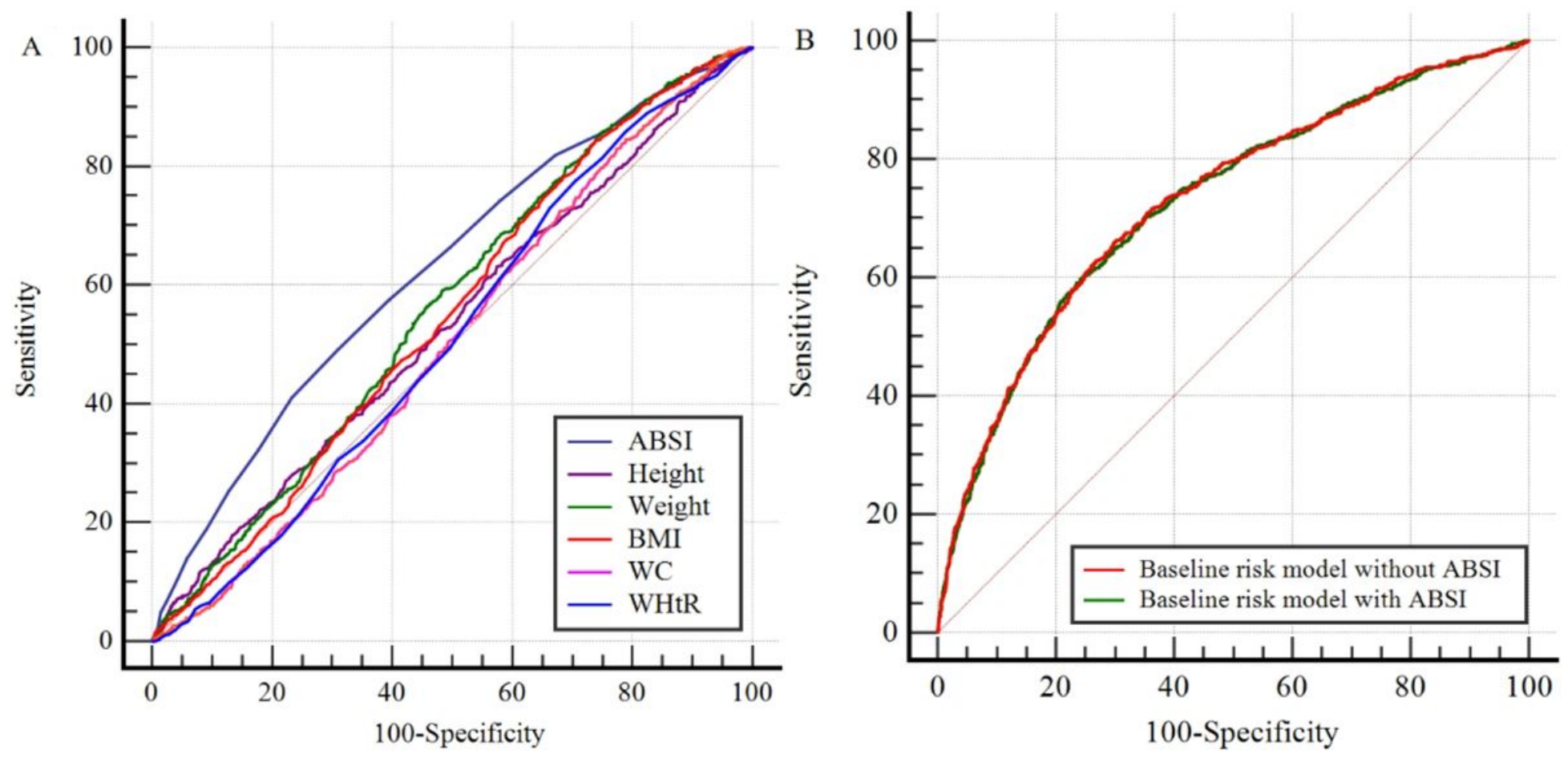

Figure 4

C-statistics evaluating incremental effect of different models

$A \rrbracket A B S I$ vs Height or Weight or BMI or WC or WHtR; B: Baseline risk model without ABSI vs Baseline risk model with ABSI

$\boldsymbol{A B S I}$ a body shape index, $B M I$ body mass index, $\boldsymbol{W} \boldsymbol{C}$ waist circumference, $\boldsymbol{W H} \boldsymbol{H} \boldsymbol{R}$ Waist-to-height ratio

The baseline risk model included age, smoking history, diabetes, hypertension, osteoporosis, systolic blood pressure, triglycerides, total cholesterol, fasting plasma glucose, hemoglobin A1c, creatinine, uric acid, alkaline phosphatase, total calcium and 25-OH-VitD3 